\title{
SURVEI INDEKS KEPUASAN MASYARAKAT PADA PELAYANAN UPTD PUSKESMAS KECAMATAN BANAWA DI KABUPATEN DONGGALA
}

\author{
Maddukelleng', Mahfuddin'2, Muhammad Wahid ${ }^{2}$ \\ ${ }^{1}$ Program Studi Sosiologi FISIP Universitas Tadulako \\ ${ }^{2}$ Program Studi Komunikasi FISIP Universitas Tadulako \\ Email: andimaddukelleng 7 @mail.com
}

\begin{abstract}
ABSTRAK
Kontrol masyarakat terhadap system pelayanan menjadi sangat penting, dimaksudkan untuk mengukur kinerja sebuah organisasi, sehingga tercipta kondisi sosial yang nyaman karena adanya sinergitas antara masyarakat dan para petugas publik. Penelitian dengan model survey sangat cocok menggunakan pendekatan kuantitatif dengan metode pengumpulan data melalui kuesioner dikuatkan dengan wawancara mendalam. Penelitian IKM (Indeks Kepuasan Masyarakat) di UPTD Puskesmas Donggala ditemukan beberapa kelemahan terutama pemanfaatan waktu pelayanan masuk kategori baik, namun catatan berkaitan dengan konsistensi waktu pelayanan dinilai masyarakat kurang optimal, baik tenaga medis maupun tenaga dokter. Sikap masyarakat terhadap tenaga medis dinilai perlu bimbingan, terutama menghadapi masyarakat dengan berbagai karakter. Hal ini dikarenakan cara penyampaian mereka kepada pasien kurang baik. Faktor yang mempengaruhi lemahnya system pelayanan itu karena petugas medis tidak memahami kondisi masyarakat yang dilayani, orang dengan pendapatan rendah, dan pendidikan rendah pasti berbeda karakter dengan yang lain. Pekerjaan bahkan turut mempengaruhi sikap seseorang ketika dilayani, hal ini penting diketahui oleh petugas lapangan yang melayani banyak masyarakat, di lokasi penelitian persoalan-persoalan seperti itu belum menjadi pegangan petugas lapangan dalam melayani masyarakat.
\end{abstract}

\section{Kata Kunci: Masyarakat; Pelayanan Publik; Survei} Submisission: 26 April 2021

\section{Pendahuluan}

Secara teori, sebuah negara dibentuk oleh masyarakat di suatu wilayah yang tidak lain bertujuan untuk memenuhi kebutuhan hidup bersama setiap anggotanya dalam koridor kebersamaan (Widowati 2014). Di kehidupan sehari-hari, kebutuhan bersama itu sering kita artikan sebagai "kebutuhan publik". SalahKesehatan merupakan salah satu sumber daya yang berguna untuk menciptakan stabilitas ekonomi dan sosial. Kesehatan yang berkualitas mampu meningkatkan usia 
harapan hidup dan meningkatkan produktivitas. Kemudian produktivitas tersebut dapat diberdayakan untuk mengakselerasi roda pembangunan menuju kesejahteraan. Guna menunjang kesejahteraan seluruh masyarakat, untuk itu pemerintah menyediakan fasilitas pelayanan jasa yang mana merupakan fasilitas yang sangat dibutuhkan oleh setiap masyarakat, utamanya fasilitas pelayanan kesehatan yaitu Puskesmas (Ningtyas 2017). Pelayanan kesehatan merupakan salah satu kebutuhan dasar dan menjadi hak setiap warga negara untuk memperolehnya sehingga pemerintah bertanggungjawab menyediakan segala bentuk upaya kesehatan yang dibutuhkan oleh seluruh warga Negara ( Zanzeno 2017). Hidup sehat dan sejahtera adalah dambaan bagi setiap manusia.

Perbaikan pelayanan publik diatur dalam banyak aturan pemerintah termasuk surat keputusan menteri didalamnya. Sejak Surat Keputusan Menteri Pendayagunaan Aparatur Negara Nomor 81 Tahun 1993 tentang Pedoman Tatalaksana Pelayanan Publik. Kemudian pada tahun 1995, Pemerintah menerbitkan kembali Instruksi Presiden Nomor 1 Tahun 1995 tentang Perbaikan dan Peningkatan Mutu Pelayanan Aparatur Pemerintah kepada Masyarakat yang kemudian dikonkritkan dengan Surat Edaran Menteri Koordinator Pengawasan Pembangunan dan Penertiban Apatur Negara Nomor 56/Wasbangpan/6/1998 tentang Langkah-langkah Nyata Memperbaiki Pelayanan Masyarakat. Pengaturan sistem pelayanan publik dianggap sudah cukup memadai, namun perjalan waktu dan perkembangan pembangunan, aturan itu semakin tidak sesuai lagi dengan kenyataan yang ada. Menurut Kotler (Lijan Poltak Sinambela, 2011: 4-5), pelayanan adalah "setiap kegiatan yang menguntungkan dalam suatu kumpulan atau kesatuan, dan menawarkan kepuasan meskipun hasilnya tidak terikat pada suatu produk secara fisik.

Melihat kenyataan itu, maka pada tahun 2014 dikeluarkan Peraturan Menteri Pendayagunaan Aparatur Negara Dan Reformasi Birokrasi No. 16 Tahun 2014 tentang Pedoman Survey Kepuasan Masyarakat Terhadap Penyelenggaraan Pelayanan Publik menggantikan Keputusan Menteri Pendayagunaan Aparatur Negara Nomor : Kep/25/M.PAN/2/2004 tentang Pedoman Pelayanan Publik Penyusunan Indeks Kepuasan Masyarakat Unit Pelayanan Instansi Pemerintah, didalamnya diatur tentang kegiatankegiatan yang harus dilakukan oleh penyelenggara pelayanan publik dalam memberikan pelayanan yang bermutu. Di mana salah satu kegiatannya yaitu melakukan Survey Kepuasan Masyarakat, untuk mengevaluasi apakah sistem maupun aturan yang telah dibuat itu masih sesuai atau perlu revisi kembali mengikuti perkembangan zaman yang semakin modern.

Peran penting untuk mengoptimalkan pelayan publik tentu terkait erat dengan fungsi utama pemerintah sebagai pelayan masyarakat sehingga pemerintah perlu terus berupaya meningkatkan kualitas pelayanan. Ukuran keberhasilan penyelenggaraan pelayanan ditentukan oleh tingkat kepuasan penerima pelayanan. Kepuasan penerima pelayanan dicapai apabila penerima 
pelayanan memperoleh pelayanan sesuai dengan dibutuhkan yang diharapkan. Menurut Kasmir (2005:3), Faktor utama yang mempengaruhi pelayanan adalah sumber daya manusia. Artinya peranan manusia (karyawan) yang melayani masyarakat merupakan faktor utama karena hanya dengan manusialah pelanggan dapat berkomunikasi secara langsung dan terbuka.

Salah satu upaya yang harus dilakukan dalam upaya peningkatan kualitas pelayanan publik adalah dengan melakukan pengukuran IKM. IKM merupakan salah satu tolak ukur bagi instansi pemerintah dalam melakukan evaluasi pelayanan yang diberikan pada masyarakat agar pelayanan yang diberikan kepada masyarakat tetap prima, Upaya meningkatkan jumlah kunjungan dan tingkat kepuasan masyarakat terhadap pelayanan publik diPuskesmas, sangat memerlukan kesigapan petugas kesehatan dalam melayani kunjungan masyarakat (Nesimnasi, 2019).

Dalam rangka meningkatkan kinerja pelayanan pemerintahan di lingkungan Pemerintah Provinsi maupun Kota/Kabupaten, maka Pemerintah harus melaksanakan pengukuran berkaitan dengan "Kepuasan Masyarakat". Survey Kepuasan Masyarakat bertujuan untuk mendapatkan feed back/ umpan balik atas kinerja/kualitas pelayanan yang diberikan kepada masyarakat guna perbaikan/peningkatan kinerja/kualitas pelayanan secara berkesinambungan. Program ini diselenggarakan untuk melaksanaan Peraturan Menteri Pendayagunaan Aparatur Negara dan Reformasi Birokrasi Nomor 16 Tahun 2014 tentang Pedoman Survey
Kepuasan Masyarakat Terhadap Penyelanggaraan Pelayanan Publik. Kebijakan ini merupakan salah satu upaya Pemerintah dalam mewujudkan kepemimpinan yang baik (good governance).

Pemerintah daerah sebagai penyedia layanan publik bertanggung jawab dan terusberupaya untuk memberikan pelayanan yang terbaik kepada masyarakat. Rendahnya mutu Sebagian masyarakat yang pernah berurusan dengan birokrasi selalu mengeluh dan kecewa terhadap layanan yang berikan. Ada sebagian masyarakat sampai saat ini masih menganggap rendah terhadap kinerja birokrasi(Saputra, 2016).

Di Sulawesi Tengah, Pemerintah mengakui masih banyak sorotan terkait pelayanan publik sehingga perlu dibenahi oleh seluruh aparatur sipil negara di lingkungan pemerintah setempat. "Kinerja aparatur pemerintah di bidang pelayanan masih menjadi sorotan masyarakat. Berbagai langkah telah dilakukan kearah perbaikan dan peningkatan kualitas pelayanan, namun hasilnya belum optimal dirasakan oleh masyarakat selama ini. Kondisi tersebut dapat dilihat antara lain dari sistem dan prosedur pelayanan yang masih berbelitbelit, jangka waktu penyelesaian pelayanan yang tidak pasti, informasi pelayanan yang tidak transparan serta sikap dan perilaku petugas atau aparatur yang kurang profesional, Ungkap Derry Djanggola diakhir jabatannya sebagai Sekpro Sulawesi Tengah, menyampaikan bahwa kita masih menyimpan pekerjaan berat untuk kita selesaikan bersama. Tingkat pelayanan yang paling tinggi intensitasnya adalah 
kantor Dinas Dukcapil, kantor pelayanan kesehatan terutama di puskesmas, dan kantor pelayanan publik lainnya. Karena itu kajian ini ingin memfokuskan pada pelayanan kesehatan terutama di Puskesmas-puskemas di kabupaten Donggala sebagai salah kabupaten yang masih dirasakan rendah sistem pelayanannya, dengan mengacu pada Peraturan Menteri Pendayagunaan Aparatur Negara Dan Reformasi Birokrasi Republik Indonesia Nomor 14 Tahun 2017, Tetang Pedoman Survey Kepuasan Masyarakat Terhadap Penyelenggaraan Pelayanan Publik dengan 9 indikator.

\section{Metode Penelitian}

Penelitian ini sifatnya kuantitatif, data terkumpul melalui kuesioner/angket. Angket yang digunakan adalah jenis angket tertutup yang sudah disediakan alternatif jawaban sehingga responden hanya memilih salah satu jawaban yang tersedia. Teknik sampling yang digunakan dalam penelitian ini adalah accidental sampling, yaitu teknik penentuan sampel berdasarkan faktor spontanitas, artinya siapa saja yang secara tidak sengaja bertemu dengan peneliti di lokasi penelitian dan sesuai dengan karakteristik atau ciri-ciri yang telah ditetapkan yaitu masyarakat yang pernah dilayani pada UPTD Puskesmas di
Kabupaten Donggala, maka orang tersebut dapat digunakan sebagai sampel (responden). Sampel penelitian 100 responden sesuai dengan jumlah minimal responden dalam penyusunan Indeks Kepuasan Masyarakat. Berikut indikator yang diukur sbb :

Tabel 1

Indikator yang diukur pada IKM

\begin{tabular}{|c|c|c|c|c|}
\hline Komponen & \multicolumn{2}{|r|}{ Indikator } & No.Butir & Jumlah \\
\hline \multirow{9}{*}{$\begin{array}{l}\text { Indeks } \\
\text { Kepuasan } \\
\text { Pelanggan }\end{array}$} & & $\begin{array}{l}\text { Persyaratan } \\
\text { pelayanan }\end{array}$ & 1,2 & 2 \\
\hline & 2. & $\begin{array}{l}\text { Prosedur } \\
\text { pelayanan }\end{array}$ & 3,4 & 2 \\
\hline & 3 . & $\begin{array}{l}\text { Waktu } \\
\text { pelayanan }\end{array}$ & 5,6 & 2 \\
\hline & 4. & $\begin{array}{l}\text { Biaya } \\
\text { pelayanan }\end{array}$ & 7 & 1 \\
\hline & 5. & $\begin{array}{l}\text { Produk } \\
\text { Spesifikasi } \\
\text { Jenis Pelayanan }\end{array}$ & 8 & 1 \\
\hline & 6. & $\begin{array}{l}\text { Kompetensi } \\
\text { Pelayanan }\end{array}$ & 9,10 & 2 \\
\hline & 7. & $\begin{array}{l}\text { Perilaku } \\
\text { Pelaksana }\end{array}$ & 11,12 & 2 \\
\hline & & $\begin{array}{l}\text { Maklumat } \\
\text { Pelayanan }\end{array}$ & 13 & 1 \\
\hline & 9. & $\begin{array}{l}\text { Penanganan } \\
\text { Pengaduan, } \\
\text { Saran dan } \\
\text { Masukan }\end{array}$ & 14,15 & 2 \\
\hline \multicolumn{3}{|r|}{ ir soal } & 15 & 15 \\
\hline
\end{tabular}


Instrumen penelitian ini Setuju, $\mathrm{S}=$ Setuju, TS $=$ Tidak Setuju, menggunakan alat ukur skala bertingkat $\quad$ STS = Sangat Tidak Setuju. Berikut ini dengan 4 skala pengukuran atau dengan tabel menunjukkan skala bobot penilaian 4 alternatif jawaban, yaitu SS = Sangat yang digunakan:

\section{Tabel 2}

Skala Bobot Penilaian

\begin{tabular}{|l|l|c|}
\hline No & \multicolumn{1}{|c|}{ Kriteria Penliaian Bobor } & Bobot \\
\hline 1 & Sangat Setuju & 4 \\
\hline 2 & Setuju & 3 \\
\hline 3 & Tidak Setuju & 2 \\
\hline 4 & Sangat Tidak Setuju & 1 \\
\hline
\end{tabular}

Analisis IKM dan Interpretasi data, berdasarkan KEPMENPAN nomor 14 tahun 2017 tentang Pedoman Umum Penyusunan Indeks Kepuasan Masyarakat, terdapat 9 unsur atau

indikator yang dikaji dalam penghitungan IKM. Setiap unsur pelayanan mempunyai penimbang yang sama dengan rumus sebagai berikut

\begin{tabular}{|l|l|}
\hline Bobot nilai rata-tara tertimban $=\frac{\text { Jumlah bobot }}{\text { Jumlah Unsur }}=\frac{1}{9}$ \\
\hline
\end{tabular}

Guna memperoleh nilai IKM digunakan rumus sebagai berikut :

IKM $=\frac{\text { Total dari nilai persepsi per unsur }}{\text { Total unsur yang terisi }} \quad X$ nilai penimbang

Guna mempermudah interpretasi nilai IKM yang berkisar 25-100, sesuai dengan ketentuan dalam KEPMENPAN nomor 25 tahun 2004 tentang Pedoman Umum Penyusunan Indeks Kepuasan Masyarakat, maka hasil penilaian tersebut di atas dikonversikan dengan nilai dasar 25 , dengan rumus sebagai berikut:

\section{Nilai komversi IKM = Nilai IKM Uni Pelayanan X 25}


Hasil perhitungan tersebut kemudian dikategorikan sesuai dengan nilai persepsi dan interval nilai IKM seperti pada tabel sebagai berikut:

Tabel 3

Nilai Persepsi, Interval IKM, Interval Konversi IK

\begin{tabular}{|c|c|c|c|c|}
\hline $\begin{array}{c}\text { Nilai } \\
\text { Persepsi }\end{array}$ & $\begin{array}{c}\text { Nilai Interval } \\
\text { IKM }\end{array}$ & $\begin{array}{c}\text { Nilai Interval } \\
\text { Konversi IKM }\end{array}$ & $\begin{array}{c}\text { Mutu } \\
\text { Pelayanan }\end{array}$ & $\begin{array}{c}\text { Kinerja Unit } \\
\text { Pelayanan }\end{array}$ \\
\hline 1 & $1,00-1,75$ & $25-43,75$ & D & Tidak baik \\
\hline 2 & $1,76-2,50$ & $43,76-62,50$ & C & Kurang baik \\
\hline 3 & $2,51-3,25$ & $62,51-81,25$ & B & Baik \\
\hline 4 & $3,26-4,00$ & $81,26-100,00$ & A & Sangat Baik \\
\hline \multicolumn{4}{|c}{ (KEPMENPAN NomorKEP/25/M.PAN/2/2004) } \\
\hline
\end{tabular}

Guna mendapatkan nilai rata-rata tertimbang per unsur pelayanan, jumlah nilai rata-rata per unsur pelayanan dikalikan dengan 0,11 sebagai nilai bobot rata-rata tertimbang. Sedangkan nilai indeks komposit (gabungan) untuk setiap unit pelayanan, merupakan jumlah nilai rata-rata dari setiap unsur pelayanan dikalikan dengan penimbang yang sama, yaitu 0,11. Hasil dari nilai indeks komposit (gabungan) tersebut merupakan nilai IKM dari Pelayanan Puskesmas. Langkah terakhir dalam teknik analisis data adalah menarik kesimpulan dari hasil penelitian dan pembahasan. Data yang berupa angka dari hasil angket dijelaskan dalam bentuk kalimat, sehingga diperoleh deskripsi hasil penelitian.

\section{Hasil dan Pembahasan}

Berdasarkan pengukuran terhadap 9 unsur pelayanan (U) dengan jumlah responden 100 orang, diperoleh perhitungan Indeks Kepuasan Masyarakat (IKM) pada Puskesmas mengacu pada data pengolahan Indeks Kepuasan Masyarakat per-unsur pelayanan adalah sebagai berikut:

\section{Tabel 4}

Menghitung nilai rata-rata per unsur layanan (Rata-rata Skor) $=\sum \underline{\text { F.X }}$

\begin{tabular}{|l|l|c|c|}
\hline No. & \multicolumn{1}{|c|}{ Unsur Yang Dinilai } & $\begin{array}{c}\text { Jml Nilai } \\
\text { Perunsur (Skor) }\end{array}$ & $\begin{array}{c}\text { Nilai Rata-Rata } \\
\text { Unsur (NRR) }\end{array}$ \\
\hline 1 & Persyaratan pelayanan (U1) & 297 & 2,97 \\
\hline 2 & Prosedur pelayanan (U2) & 300 & 3 \\
\hline 3 & Waktu pelayanan (U3) & 285 & 2,85 \\
\hline 4 & Biaya/Tarif (U4) & 301 & 301 \\
\hline 5 & Produk spesifikasi jenis pelayanan (U5) & 300 & 3 \\
\hline
\end{tabular}




\begin{tabular}{|c|l|c|c|}
\hline 6 & Kompetensi Pelaksana Pelayanan (U6) & 303,5 & 304 \\
\hline 7 & Perilaku Pelaksana pelayanan (U7) & 299,5 & 2,99 \\
\hline 8 & Maklumat Pelayanan (U8) & 302 & 3,02 \\
\hline 9 & $\begin{array}{l}\text { Penanganan pengaduan, saran dan } \\
\text { masukan (U9) }\end{array}$ & 301 & 3,01 \\
\hline
\end{tabular}

Sumber : Data diolah 2020

Menghitung Nilai Rata-Rata (NRR) tertimbang

NRR tertimbang= NRR per-unsur $\mathrm{x} 0,11(\mathrm{P})$

Angka 0,11(P) merupakan hasil pembagi nilai setiap unsur $=1$ dibagi jumlah unsur untuk mendapatkan nilai rata-rata tertimbang. Untuk mendapatkan nilai IKM rata- rata dikali 25. Hasil perhitungan NRR tertimbang $=$ Nilai Perunsur $(\mathrm{S}) \mathrm{x}$ persentasi jumlah unsur yang dikelolah (P) sebagai berikut:

\section{Tabel 5}

Tanggapan Respon terhadap Nilai Per-unsur dan Nilai Rata Tertimbang

\begin{tabular}{|l|l|c|c|}
\hline No & \multicolumn{1}{|c|}{ Unsur Yang Dinilai } & $\begin{array}{c}\text { Nilai Perunsur } \\
\text { (Skor) }\end{array}$ & $\begin{array}{c}\Sigma \text { NRR } \\
\text { tertimbang }\end{array}$ \\
\hline 1 & Persyaratan pelayanan (U1) & 2,97 & 0,32 \\
\hline 2 & Prosedur pelayanan (U2) & 3 & 0,33 \\
\hline 3 & Waktu pelayanan (U3) & 2,85 & 0,31 \\
\hline 4 & Biaya/Tarif (U4) & 301 & 0,33 \\
\hline 5 & Produk spesifikasi jenis pelayanan (U5) & 3 & 0,33 \\
\hline 6 & Kompetensi Pelaksana Pelayanan (U6) & 304 & 0,33 \\
\hline 7 & Perilaku Pelaksana pelayanan (U7) & 2,99 & 0,32 \\
\hline 8 & Maklumat Pelayanan (U8) & 3,02 & 0,33 \\
\hline 9 & Penanganan pengaduan, saran dan masukan (U9) & 3,01 & 0,33 \\
\hline \multicolumn{2}{|c|}{$\Sigma$ NRR tertimbang } & $\mathbf{2 , 9 3}$ \\
\hline
\end{tabular}

Sumber : Data diolah 2020

$\Sigma$ NRR tertimbang $=$ jumlah keseluruhan nilai tertimbang $=\mathbf{2 , 9 3}$ 
Menghitung Nilai Indeks Kepuasan Masyarakat Guna memudahkan interpretasi terhadap penilaian IKM antara rentang nilai 25-100, maka hasil penilaian nilai ratarata tertimbang ( $\Sigma$ NRR tertimbang) di atas dikonversikan dengan nilai dasar 25 , dengan rumus sebagai berikut:

\section{Nilai Konversi IKM $=\Sigma$ NRR tertimbang $\times 25$}

Nilai Konversi IKM = 2,93 x $25=\mathbf{7 3 , 2 5}$

Selajutnya, hasil nilai Konversi Indeks Kepuasan Masyarakat (IKM) UPTD Puskesmas Banawa Kabupaten Donggala, disesuaikan dengan kategorisasi mutu pelayanan berdasarkan indeks yang ditunjukkan pada tabel di bawah ini. sebagai berikut :

Tabel 6

Kategorisasi Mutu Pelayanan

\begin{tabular}{|c|c|c|c|}
\hline $\begin{array}{c}\text { Nilai Interval } \\
\text { IKM }\end{array}$ & $\begin{array}{c}\text { Nilai Interval } \\
\text { Konversi }\end{array}$ & $\begin{array}{c}\text { Mutu } \\
\text { Pelayanan }\end{array}$ & $\begin{array}{c}\text { Kinerja Unit } \\
\text { Pelayanan }\end{array}$ \\
\hline $1,00-1,75$ & $25,00-43,75$ & $\mathrm{D}$ & TIDAK BAIK \\
\hline $1,76-2,50$ & $43,76-62,50$ & $\mathrm{C}$ & KURANG BAIK \\
\hline $2,51-3,25$ & $\mathbf{6 2 , 5 1 - 8 1 , 2 5}$ & $\mathbf{B}$ & BAIK \\
\hline $3,26-4,00$ & $81,26-100,00$ & $\mathrm{~A}$ & SANGAT BAIK \\
\hline
\end{tabular}

Berdasarkan kategorisasi mutu pelayanan pada tabel 6 di atas, maka Puskesmas UPTD Kabupaten Donggala memperoleh hasil Konversi IKM sebesar 73,25 . Kinerja unit pelayanan Puskesmas berada dalam mutu pelayanan "B" dengan kategori "BAIK". Nilai baik merupakan hasil keseluruhan nilai IKM pada pelayanan puskesmas di UPTD Puskesmas Kecamatan Banawa Kab. Donggala, menjadi gambaran bahwa rata-rata perlakukan atau pelayanan yang dilakukan di puskesmas ini tergolong baik, walaupun masih banyak keluhan masyarakat yang perlu terus diakomodir. Seperti pembayaran berupa pembelian obat, atau mereka di suruh ke apotek luar untuk membeli obat, hal ini terlihat bahwa informasi berkaitan dengan pembayaran itu belum sampai kepada masyarakat.

Penililaian lain dari responden berkaitan dengan waktu pelayanan yang sudah diteta pkan dengan jelas, tetapi tenaga medis terutama dokter seringkali lambat datang. Dampaknya antrian sering terjadi. Antrian disebabkan oleh kelambatan dokter, ditambah kursi tempat duduk yang tidak memadai, padahal jadual pelayanannya jam 8.00 pagi dokter datangnya kadang jam 10.00 siang. 
Untuk menilai IKM dari setiap unsur pelayanan, maka nilai IKM/jumlah keseluruhan nilai (skor) tanggapan responden yang memberi nilai antara (1 s/d 4 ), hasilnya dikonversi, dengan langsung mengalikan 25, maka nilai konversi IKM dapat ditemukan seperti terlihat pada tabel berikut:

Tabel 7

Hasil Indeks Kepuasan Masyarakat Perunsur Pelayanan

\begin{tabular}{|l|l|c|c|c|c|}
\hline No & \multicolumn{1}{|c|}{ Unsur Pelayanan } & $\begin{array}{c}\text { Nilai } \\
\text { IKM }\end{array}$ & $\begin{array}{c}\text { Nilai } \\
\text { Konversi } \\
\text { IKM }\end{array}$ & $\begin{array}{c}\text { Mutu } \\
\text { Pelaya } \\
\text { nan }\end{array}$ & Kinerja \\
\hline 1 & Persyaratan pelayanan (U1) & 2,97 & 74,25 & B & Baik \\
\hline 2 & Prosedur pelayanan (U2) & 3 & 75 & B & Baik \\
\hline 3 & Waktu pelayanan (U3) & 2,85 & 71,25 & B & Baik \\
\hline 4 & Biaya/Tarif (U4) & 3,01 & 75,25 & B & Baik \\
\hline 5 & $\begin{array}{l}\text { Produk spesifikasi jenis pelayanan } \\
\text { (U5) }\end{array}$ & 3 & 75 & B & Baik \\
\hline 6 & $\begin{array}{l}\text { Kompetensi Pelaksana Pelayanan } \\
\text { (U6) }\end{array}$ & 3,04 & 76 & B & Baik \\
\hline 7 & Perilaku Pelaksana pelayanan (U7) & 2,99 & 74,75 & B & Baik \\
\hline 8 & Maklumat Pelayanan (U8) & 3,02 & 75,5 & B & Baik \\
\hline 9 & $\begin{array}{l}\text { Penanganan pengaduan, saran dan } \\
\text { masukan (U9) }\end{array}$ & 3,01 & 75,25 & B & Baik \\
\hline
\end{tabular}

Sumber: Data primer diolah 2020

Berdasarkan hasil survey kepuasan masyarakat terhadap pelayanan Publik Pemerintah Kabupaten Donggala yang telah dilakukan, selanjutnya diperoleh indikator kepuasan masyarakat yang meliputi rata-rata kepuasan terhadap pelayanan yang dirasakan oleh masyarakat (mean performance), ratarata harapan masyarakat terhadap pelayanan Publik yang diterima (mean importance), diagram Importance Performance Analysis (IPA Diagram) yang menunjukkan posisi masingmasing dimensi pelayanan pada sebuah diagram serta indeks kepuasan pelanggan (Customer Statisfaction Index /CSI). 
Tabel 8

Mean Performance, Mean Importance, Nilai GAP dan CSI

Pelayanan Publik di Puskesmas.

\begin{tabular}{|c|l|r|r|r|r|r|}
\hline No & \multicolumn{1}{|c|}{ Atribut Kepuasan } & \multicolumn{1}{c|}{$\begin{array}{c}\text { Mean } \\
\text { Performance }\end{array}$} & $\begin{array}{c}\text { Mean } \\
\text { Importance }\end{array}$ & GAP & \multicolumn{1}{c|}{$\begin{array}{c}\text { CS } \\
\text { Indekx }\end{array}$} & Ket. \\
\hline 1 & $\begin{array}{l}\text { Persyaratan pelayanan } \\
\text { (U1) }\end{array}$ & 2,97 & 4,00 & $-1,03$ & 74,25 & Baik \\
\hline 2 & Prosedur pelayanan (U2) & 3 & 3,95 & $-0,95$ & 75 & Baik \\
\hline 3 & Waktu pelayanan (U3) & 2,85 & 3,85 & $-0,65$ & 71,25 & Baik \\
\hline 4 & Biaya/Tarif (U4) & 3,01 & 3,95 & $-0,94$ & 75,25 & Baik \\
\hline 5 & $\begin{array}{l}\text { Produk spesifikasi jenis } \\
\text { pelayanan (U5) }\end{array}$ & 3 & 3,96 & -33 & 75 & Baik \\
\hline 6 & $\begin{array}{l}\text { Kompetensi Pelaksana } \\
\text { Pelayanan (U6) }\end{array}$ & 3,04 & 4,00 & $-0,96$ & 76 & Baik \\
\hline 7 & $\begin{array}{l}\text { Perilaku Pelaksana } \\
\text { pelayanan (U7) }\end{array}$ & 2,99 & 4,00 & -1.01 & 74,75 & Baik \\
\hline 8 & $\begin{array}{l}\text { Maklumat Pelayanan } \\
\text { (U8) }\end{array}$ & 3,02 & 3,90 & $-0,88$ & 75,5 & Baik \\
\hline 9 & $\begin{array}{l}\text { Penanganan pengaduan, } \\
\text { saran dan masukan (U9) }\end{array}$ & 3,01 & 4,00 & $-0,99$ & 75,25 & Baik \\
\hline Rata-Rata Keseluruhan & 2,99 & 7,37 & $-4,38$ & 74,75 & Baik \\
\hline
\end{tabular}

Tabel 8 menunjukkan bahwa secara Publik, masyarakat yang datang ke puskesmas merasa puas terhadap pelayanan Publik yang diberikan oleh UPTD Puskesmas di Kecamatan Banawa dengan nilai indeks kepuasan sebesar 74,25 masuk dalam kategori baik. Terdapat tiga jenis atribut pelayanan Publik yang memiliki indeks kepuasan dibawah rata-rata yaitu waktu pelayanan, Persyartaan pelayanan dan perilaku pelaksanan pelayanan dengan nilai indeks 74,25, 71,25, dan 74,75. Hanya satu unit pelayanan yang bernilai sedikit lebih baik yakni kompetensi pelaksana pelayanan dengan nilai 76 masuk kategori baik. Melihat kondisi seperti itu, maka perlu adanya menekanan pada personil pelayanan seperti tenaga kedokteran yang paling banyak disoroti, persyaratan dan keramahan tenagatenaga yang bertugas untuk menghadapi orang-orang yang datang, apalagi mereka ini orang kampung yang tingkat pendidikannya masih rendah dan penghasilan masih jauh dari harapan. 
Berikut ini merupakan penjelasan tiap unsur dari hasil Survey Kepuasan Masyarakat di pelayanan publik khususnya di UPTD Puskesmas Banawa Kecamatan Banawa Kabupaten Donggala sebagai berikut :

1. Unsur Persyaratan (U1)

Pada tabel 8 tersebut menunjukan nilai rata - rata performance untuk unsur persyaratan sebesar 2,97 dan nilai GAP -1,03 dengan indeks kepuasan untuk unsur persyaratan sebesar 74,25 maka untuk unsur Pesyaratan pelayanan di UPTD Puskesmas Kecamatan Banawa termasuk dalam kategori "Baik". Meskipun unsur persyaratan dalam pelayanan menurut masyarakat baik, akan tetapi masih ada beberapa responden yang meyatakan bahwa Persyaratan pelayanan di Puskesmas Banawa ini dirasa tidak sesuai dan kurang sesuai, sehingga responden harus bolakbalik untuk melakukan pengurusan dokumen karena ada persyaratan yang belum terpenuhi, terutama berkaitan dengan BPJS, pengambilan obat di luar puskesmas.

\section{Tabel 9}

Persepsi Responden terhadap ketidakpuasan terhadap unsur Persayaratan

\begin{tabular}{|l|l|c|}
\hline No. & \multicolumn{1}{|c|}{ Persepsi Responden } & Persentase \\
\hline 1 & $\begin{array}{l}\text { Persyaratan yang disampaiakan petugas kurang jelas, } \\
\text { sehingga responden harus berkali-kali untuk melengkapi } \\
\text { persyaratan }\end{array}$ & 1,9 \\
\hline 2 & $\begin{array}{l}\text { Persyaratan sudah jelas, tetapi dokumen tidak segera } \\
\text { disetujui }\end{array}$ & 0,30 \\
\hline 3 & Persyaratan adminitratif Banyak dan susah untuk dipenuhi & 2 \\
\hline \multicolumn{1}{|c|}{ Total } & 4,2 \\
\hline
\end{tabular}

2. Unsur Prosedur (U2)

Pada tabel 8 menunjukan nilai rata - rata performance untuk unsur prosedur sebesar 3,0 dan nilai GAP $-0,09$ dan dengan indeks kepuasan untuk unsur prosedur sebesar 75 , maka untuk unsur Prosedur pelayanan di Puskesmas Banawa termasuk dalam kategori "Baik". Meskipun prosedur pelayanan menurut responden baik, akan tetapi masih ada respoden, yang mengatakan bahwa prosedur pelayanan di Puskesmas Banawa kurang mudah dipahami dan petugas melayani tidak sesuai dengan prosedur. Kedua hal tersebut bisa jadi merupakan suatu sebab akibat dimana prosedur pelayanan 
Publik yang ada saat ini tidak mudah dipahami oleh masyarakat sehingga masyarakat menganggap atau menyangka petugas melayani tidak sesuai dengan prosedur yang berlaku. Masih ditemukan adanya nomor titipan dari petugas, lambat datang tapi dilayani lebih awal alasannya ada nomor antrian.

\section{Tabel 10}

Persepsi Responden terhadap ketidak puasan terhadap unsur Prosedur

\begin{tabular}{|l|l|c|}
\hline No. & \multicolumn{1}{|c|}{ Persepsi Responden } & Persentase \\
\hline 1 & $\begin{array}{l}\text { Prosedur Pelayanan banyak dan sulit dipahami oleh } \\
\text { respoden }\end{array}$ & 0,9 \\
\hline 2 & $\begin{array}{l}\text { Ketika terdapat permasalahan pada dokumen yang di urus } \\
\text { responden, petugas kurang bisa memberikan solusi dan } \\
\text { melimpahkan permasalahan tersebut ke petugas lainya. }\end{array}$ & 0,50 \\
\hline 3 & $\begin{array}{l}\text { Petugas melayani tidak sesuai prosedur terutama untuk } \\
\text { petugas yang mengatur nomor antrian untuk mendapatkan } \\
\text { pelayanan }\end{array}$ & 1 \\
\hline \multicolumn{1}{|c|}{ Total } \\
\hline
\end{tabular}

3. Waktu Pelayanan (U3)

Pada tabel 8 menunjukan nilai rata - rata performance untuk unsur waktu pelayanan sebesar 2,85 dan nilai GAP -0,65 dengan indeks kepuasan untuk unsur persyaratan sebesar 71,25 maka untuk unsur Waktu pelayanan di Puskesmas Banawa termasuk dalam kategori "Baik". Meskipun Waktu pelayanan menurut responden baik, akan tetapi masih ada respoden yang mengatakan bahwa waktu penyelesaian dokumen lama dan tidak sesuai dengan yang disampaikan petugas. Selain proses administrasi juga kelambatan pelayanan dari dokter jaga, hal itu disebabkan tempat tinggi dokter di Palu. Pada tabel 10 terlihat beberapa alasan kenapa responden merasa tidak puas terhadap atribut waktu pelayanan.

\section{Tabel 11}

Persepsi Responden terhadap ketidakpuasan terhadap unsur Waktu Pelayanan

\begin{tabular}{|l|c|c|c|}
\hline No. & \multicolumn{2}{|c|}{ Persepsi Responden } & Persentase \\
\hline 1 & Waktu penyelesaian dokumen lama dan tidak sesuai & 0,9 \\
\hline
\end{tabular}




\begin{tabular}{|l|l|c|}
\hline & dengan waktu ditentukan & \\
\hline 2 & $\begin{array}{l}\text { Dokumen tidak segera di proses atau di setujui petugas } \\
\text { sehingga harus menggu lagi }\end{array}$ & 1,30 \\
\hline 3 & Pelayanan dokter setelah proses administrasi juga lambat & 2,09 \\
\hline \multicolumn{2}{|c|}{ Total } & 4,29 \\
\hline
\end{tabular}

4. Unsur Biaya atau Tarif Pelayanan (U4)

Pada tabel 8 menunjukan nilai rata - rata performance untuk unsur Biaya atau tarif pelayanan sebesar 3,01 dan nilai GAP -0,94 dan dengan indeks kepuasan sebesar 75,25 maka untuk unsur Biaya atau tarif pelayanan di Puskesmas Banawa termasuk dalam kategori "Baik". Atribut ini merupakan atribut kepuasan dengan nilai kepentingan dan kinerja/pelayanan, menurut masyarakat yang telah di Survey. Ada beberapa responden yang telah disurvey menyatakan bahwa masih ada bayaran administrasi, dan sering diarahkan kami untuk memberli obat di apotek luar puskesmas.

5. Unsur Produk Spesifikasi (U5)

Pada tabel 8 menunjukan nilai rata - rata performance untuk unsur Produk Spesifikasi jenis Pelayanan sebesar 3 dan nilai GAP -0,33 dan dengan indeks kepuasan sebesar 75 maka untuk unsur Produk Spesifikasi jenis pelayanan di Puskesmas Banawa termasuk dalam kategori "Baik". Tetapi menurut beberapa responden menyatakan masih perlu adanya poembenahan lebih baik lagi, agar pelayanan.

6. Kompetensi Pelayanan (U6)

Pada tabel 8 menunjukan nilai rata - rata performance untuk unsur Kompetensi Pelayanan sebesar 3,04 dan nilai GAP -0,96 dan dengan indeks kepuasan sebesar 76 maka untuk unsur Kompetensi pelayanan di Puskesmas Banawa termasuk dalam kategori "Baik". Tetapi menurut beberapa responden menyatakan bahwa petugas dirasa mampu memberikan pelayanan di Puskesmas Banawa. Pada tabel 11 terlihat beberapa alasan dari responden yang mengatakan bahwa kompetensi petugas yang terdiri dari kemampuan petugas dan tanggung jawab petugas di Puskesmas dirasa baik dapat memberikan pelayanan.

Tabel 12

Persepsi Responden terhadap ketidak puasan terhadap unsur Kompetensi Petugas

\begin{tabular}{|l|l|c|}
\hline No. & \multicolumn{1}{|c|}{ Persepsi Responden } & Persentase \\
\hline 1 & $\begin{array}{l}\text { Petugas dalam memberikan pelayanan sehingga proses } \\
\text { pelayanan memang lama, tetapi dirasa ada kemampuan }\end{array}$ & 0,10 \\
\hline
\end{tabular}




\begin{tabular}{|l|l|c|}
\hline & dalam hal tugas yang diberikan & \\
\hline 2 & $\begin{array}{l}\text { Petugas dapat berkomunikasi terutama dalam } \\
\text { menyampaikan informasi baik persyaratan, prosedur atau } \\
\text { lainya, walaupun kadang sedikit ada letupan emosi, } \\
\text { mungkin karena capek }\end{array}$ & 0,21 \\
\hline 3 & $\begin{array}{l}\text { Petugas cukup teliti dalam membuat dokumen sehingga } \\
\text { kesalahan dalam dokumen dapat diantisipasi }\end{array}$ & 1,99 \\
\hline \multicolumn{1}{|c|}{ Total } & 2,30 \\
\hline
\end{tabular}

7. Perilaku Pelaksana (U7)

Pada tabel 8 menunjukan nilai rata - rata performance untuk unsur Perilaku Pelaksana dalam memberikan Pelayanan sebesar 2,99 dan nilai GAP -1,01 dan dengan indeks kepuasan sebesar 74,75 maka unsur Perilaku Pelaksana di Puskesmas Banawa termasuk dalam kategori "Baik". Tetapi menurut beberapa responden menyatakan bahwa petugas dirasa kurang sopan dan ramah dalam memberikan pelayanan, kadang ada lepupan emosi saat pelayanan, terutama waktu antrian, berikut merupakan alasan responden.

Tabel 13

Persepsi Responden terhadap ketidak sesuaian/ kurang sesuai terhadap unsur

Kompetensi untuk kompetensi Petugas petugas kurang ramah dan kurang sopan.

\begin{tabular}{|l|l|c|}
\hline No. & \multicolumn{1}{|c|}{ Persepsi Responden } & Persentase \\
\hline 1 & Petugas tidak memberikan sapaan dan senyuman & 1,09 \\
\hline 2 & Petugas kurang ramah pada saat memberikan layanan & 0,30 \\
\hline 3 & Bahasa yang digunakan petugas kurang baik & 1,09 \\
\hline \multicolumn{2}{|c|}{ Total } & 2,48 \\
\hline
\end{tabular}

8. Maklumat Pelayanan (U8)

Pada tabel 8 menunjukan nilai rata - rata performance untuk unsur Maklumat Pelayanan sebesar 3,02 dan nilai GAP $-0,88$ dan dengan indeks kepuasan sebesar 75,5 maka untuk unsur Maklumat Pelayanan di Puskesmas Banawa termasuk dalam kategori "Baik". Tetapi menurut beberapa responden menyatakan bahwa petugas biasa berjanji datang jam 8.00 petugasnya datang jam 9.00 ditambah dokter juga datang lambat. Agar hal tersebut tidak terjadi lagi, Perbaikan pelayanan dapat dilakukan dengan mempercepat pelayan, tepat waktu, menyesuaikan waktu 
penyelesaian dengan keadaan pelayanan. Jika pelayanan dalam keadaan ramai maka diatur waktu yang paling baik untuk mencegah masyarakat antrian panjang, bolak-balik ke kantor pelayanan yang berarti masyarakat harus meninggalkan pekerjaan/aktivitas mereka.

9. Penanganan Pengaduan, Saran dan Masukan (U9)

Pada tabel 8 menunjukan nilai rata - rata performance untuk unsur Penanganan Pengaduan, Saran dan Masukan sebesar 3,01 dan nilai GAP -0,99 dan dengan indeks kepuasan sebesar 75,25 maka untuk unsur Penanganan Pengaduan, Saran dan Masukan di Puskesmas Banawa termasuk dalam kategori "Baik". Atribut dengan tingkat kepentingan dan kinerja/pelayanan yang dinilai baik oleh masyarakat sehingga merupakan nilai positif untuk pelayanan jasa Publik di Puskesmas. Tetapi respon negative masyarakat harus menjadi perhatian, agar ke depan bisa lebih baik.

\section{Kesimpulan}

Berikut ini merupakan beberapa hal yang dikeluhkan oleh responden selama proses mendapatkan pelayanan jasa Publik di UPTD Puskesmas Kecamatan Banawa Kabupaten Donggala sebagai berikut:

a. Hasil survey menunjukan bahwa 9 (Sembilan) indikator yang diukur berdasarkan pedoman survey, semua indikator masuk dalam kategori "Baik" dengan catatan perbaikan sesuai keluhan masing-masing indikator.

b. Temuan lain adalah, loket pendaftaran sering tidak konsisten waktu pelayanan, mestinya jam 8.00 dibukanya jam 9.00.

c. Loket ditutup tidak konsisten terlihat dari beragamnya pengalaman responden. Kadang-kadang tutup jam 12.00 siang, kadang-kadang lebih cepat, misalnya tutup jam 11 atau jam 11.30 tanpa alasan yang jelas.

d. Lama pelayanan disebabkan oleh kelambatan tenaga medis, beberapa responden mengeluh karena tenaga Dokter lambat datang. Waktu pelayanan sebenarnya mulai jam 8.00 datang kadang nanti sekitar jam 10.00. Bahkan tidak datang, sehingga kami harus bolakbalik. Hal ini terjadi karena tenaga dokter hanya satu, lalu tempat tinggal di Palu, ini merupakan kendala yang harus segera diperhatikan pemerintah daerah agar ada formasi tenaga dokter

e. Ditemukan adanya responden yang dikenakan biaya, berupa bayar obat berkisar antara $\mathrm{Rp}$ 8.000 hingga Rp 10.000 . Pembayaran ini merupakan retribusi saat pendaftaran sesuai peraturan Bupati

f. Kurangnya obat yang ada di Puskesmas, sehingga pasien 
harus membeli di apotik luar. Jika persediaan di apotik tidak ada, maka diminta pasien untuk membeli di luar, ini terjadi karena pengadaan obat-obatan yang sering terlambat.

g. Kebersihan kantor termasuk gedung dan pengecetan menjadi keluhan karena dianggap masih kurang baik dipandang mata.

h. Perlu adanya satpan agar bisa menjaga keamanan baik kendaraan maupun kemanan kantor. Menurut responden karena tidak memiliki personil pengamanan, pernah terjadi kecurian. i. Dan paling banyak dikeluhkan oleh pasien berkaitan dengan fasilitas tempat duduk, sehingga pelayanan kelihatan kurang baik karena di sana sini orang harus berdiri menunggu dilayani. Jikapun ada pengadaan kursi, ruang tunggu juga tidak memungkinkan penambahan kursi, karena itu perlu segera dilakukan pembangunan baru puskesmas.

j. Ada beberapa responden mengeluhkan keramahan pelayanan, cara bicara dan kesopan santunan agar lebih diperbaiki lagi. 


\section{Referensi}

Amin, M., \& Nasharuddin, S. Z. (2013). Hospital service quality and its effects on patient satisfaction and behavioural intention. Clinical Governance, 18(3), 238-254

Arikunto, S. (2010) Prosedur Penelitian: Suatu Pendekatan Praktik. Jakarta: Rineka Cipta.

Devi Irma Sucia Ningtyas. (2017). Analisis Kinerja Pelayanan Publik Puskesmas terhadap Indeks Kepuasan Masyarakat (Studi

Indonesia.

Kotler, P. (2000) Manajemen Pemasaran. 1st \& 2nd edn. Jakarta: Prenhalindo.

Lijan Poltak Sinambela, dkk. (2011). Reformasi Pelayanan Publik. Jakarta: Bumi Aksara.

Menteri Pendayagunaan Aparatur Negara (2004) Keputusan Menteri Pendayagunaan Aparatur Negara Nomor : Kep/25/M.Pan/2/2004 Tentang Pedoman Umum Penyusunan Indeks Kepuasan Masyarakat Unit Pelayanan Instansi Pemerintah. Indonesia.

Nesimnasi, V. (2019). Indeks Kepuasan

Masyarakat ( IKM ) Terhadap

Kualitas Pelayanan Publik Di

Puskesmas Oepoi Kota Kupang

Fakultas Kesehatan Masyarakat Universitas Nusa Cendana Fakultas
Kasus UPTD Kesehatan

Kecamatan Kepanjenkidul Kota Blitar). Jurnal Penelitian Manajemen terapan.

Kementerian Pendayagunaan Aparatur Negara dan Reformasi Birokrasi Republik Indonesia (2014) Peraturan Menteri Pendayagunaan Aparatur Negara dan Reformasi Birokrasi Nomor 16 Tahun 2014 Tentang Pedoman Survei Kepuasan Masyarakat Terhadap Penyelenggaraan Pelayanan Publik.

Kesehatan Masyarakat - Universitas Nusa Cendana. Journal of Community Health, 01(1), 2.

Peraturan Menteri Pendayagunaan Aparatur Negara Dan Reformasi Birokrasi Republik Indonesia Nomor 14 Tahun 2017, Tetang Pedoman Survey Kepuasan Masyarakat Terhadap Penyelenggaraan Pelayanan Publik

Nesimnasi, V. (2019). Indeks Kepuasan

Masyarakat ( IKM ) Terhadap

Kualitas Pelayanan Publik Di

Puskesmas Oepoi Kota Kupang Fakultas Kesehatan Masyarakat Universitas Nusa Cendana Fakultas Kesehatan Masyarakat - Universitas Nusa Cendana. Journal of Community Health, 01(1), 2.

Saputra, T. (2016). Kepuasan

Masyarakat terhadap

Penyelenggaraan Pelayanan Publik 
( Studi Kasus Kantor Kecamatan

Tambang Kabupaten Kampar ).

Jurnal Perspektif Pembiayaan Dan

Pembangunan Daerah, 4(2), 2.

Widowati, N. (2014). Analisis indeks kepuasan masyarakat (ikm) terhadap kualitas pelayanan di puskesmas bandarharjo di

Menaikkan Pangsa Pasar. Jakarta: Rineka Cipta.

Undang-Undang Nomor 25 tahun 2009 tentang Pelayanan Publik.

Yudi Zanzeno. (2017). Kinerja Unit

Pelayanan Puskesmas Di

Kabupaten Sarolangun Tahun

2018; Kajian Berdasarkan Indeks kecamatan semarang utara. Journal Of Public Policy and Management Review, 2014, 2.

Sugiyono. (2013). Metode Penelitian

Kuantitatif, Kualitatif, dan $R \& D$.

Bandung: Alfabeta

Supranto, J. (2001) Pengukuran Tingkat Kepuasan Pelanggan untuk Kepuasan Masyarakat Indikator Permenpan Nomor 14 Tahun 2017. Jurnal Khazana Intelektual. 